\title{
INFILTRAÇÃO MARGINAL DE RESINAS COMPOSTAS ASSOCIADAS A SISTEMAS ADESIVOS COM E SEM CARGA
}

\author{
MARGINAL LEAKAGE OF COMPOSITE RESINS ASSOCIATED TO \\ ADHESIVE SYSTEMS WITH AND WITHOUT LOAD
}

\author{
Osvaldo Benoni da Cunha Nunes \\ Paulo Humaitá de Abreu
}

NANCy Alfieri Nunes

Monclair Vitório Portolani Junior

Cézar Pereira Berne
Professor Doutor da Disciplina de Dentística da Faculdade de Odontologia de Lins (FOL/UNIMEP)

Professor Doutor da Disciplina de Materiais Dentários da Faculdade de Odontologia de Lins (FOL/UNIMEP)

Professora Doutora da Disciplina de Estomatologia da Faculdade de Odontologia de Lins (FOL/UnimeP)

Mestre em Odontologia na área de Prótese pela Faculdade de Odontologia de Bauru (Unesp/Araraquara)

Acadêmico da Faculdade de Odontologia de Lins (FOL/ UNIMEP)

\section{Resumo}

O objetivo desta pesquisa foi verificar o grau de infiltração marginal em cavidades classe V, vestibular e lingual, em 30 dentes pré-molares humanos recém extraídos e divididos em três grupos, os quais, após ciclagem térmica a $5^{\circ} \mathrm{C} / 55^{\circ} \mathrm{C}$ e corados com o azul de metileno a $2 \%$, foram avaliados sob dois aspectos: 1) tipos de adesivos dentinários: adesivo autocondicionante (sem carga) e restaurados com resina composta micro-híbrida; adesivo de frasco único (com carga), no qual foi feito ataque ácido e restaurados com resina composta micro-híbrida; e 2) localização da parede cavitária (parede oclusal em esmalte e parede gengival em cemento). Os dados foram mensurados por meio de escores de 0 a 4 e processados estatisticamente pelo teste não paramétrico de Kruskal-Wallis, a fim de demonstrar o mais eficiente adesivo dentinário e a parede cavitária que menos permitiu a infiltração do corante.

Palavras-chave: INFILTRAÇÃO MARGINAL - ADESIVOS DENTINÁRIOS - RESINAS COMPOSTAS.

\section{Abstract}

The objective of this research was to verify the degree of marginal infiltration in class- $V$, vestibular, and lingual cavities in 30 recently-extracted human premolar teeth, divided into four groups, which, after the thermal cycle at $5^{\circ} \mathrm{C} / 55^{\circ} \mathrm{C}$, and stained with $2 \%$ methylene blue, were assessed in two ways: 1 - types of dentin bonding: self-etching adhesive (no load) and restored with micro-hybrid composite resin, one-bottle adhesive (with load), on which acid attack was conducted, and which was restored with micro-hybrid composite resin, and 2 - location of the cavity wall (enamel occlusal wall and cement gingival wall). The data were measured through scores of 0 to 4 and statistically analyzed by nonparametric Kruskal-Wallis test to demonstrate the most effective dentin adhesive and determine which cavity wall that allowed less dye leakage.

Keyword: MARGINAL LEAKAGE - DENTIN ADHESIVE - COMPOSITE RESIN. 


\section{INTRODUÇÃO}

A partir dos estudos de Nakabayashi, ${ }^{1}$ surgiu um sistema inovador de adesão à dentina, o qual se baseia no condicionamento ácido total (esmalte/ dentina), seguido da utilização de um primer hidrofílico e de um adesivo, levando à formação de uma zona mista de resina/dentina, que tem sido chamada de camada híbrida. ${ }^{2}$

A maior importância do condicionamento ácido de dentina reside no fato de contribuir para a obtenção de uma forte adesão à dentina, além de reduzir qualquer fenda entre a parede da cavidade e o material restaurador, minimizando, assim, a microinfiltração que ainda é um dos principais problemas a ser superado para a manutenção da vitalidade pulpar. ${ }^{3}$

Os adesivos dentinários, responsáveis por essa união, são moléculas orgânicas multifuncionais, que contém grupos reativos que interagem com a dentina e com o monômero da resina restauradora, os quais podem ser classificados em cinco gerações.

Os adesivos de primeira geração ${ }^{4}$ apresentavam uma adesão muito pobre à dentina. Num primeiro momento, esses adesivos serviram para completa remoção de smear layer e penetração de tags de resina nos túbulos dentinários. O componente básico desses adesivos (metacrilato) formava uma união química muito frágil com os íons cálcio da dentina. A união promovida pelos adesivos de primeira geração hidrolisava e provocava microinfiltração.

Assim, foram substituídos por uma geração mais avançada, isto é, os adesivos de segunda geração, ${ }^{3}$ os quais foram referidos como adesivos fosfatados, havendo, então, a substituição do metacrilato pelo BIS-GMA. Primeiramente, foram adicionados fosfatos polimerizáveis a BIS-GMA, promovendo a união cálcio/fosfato e, por isso, designados adesivos fosfatados.
Já os sistemas adesivos de terceira geração ${ }^{3}$ passaram a realizar na dentina as transformações necessárias para que houvesse maior efetividade na união, obtendo, em razão disso, maior adesão. Vários agentes condicionadores de dentina que modificam ou removem a smear layer interagem com a dentina superficial para compor um mecanismo de tratamento. Na maioria dos agentes adesivos de terceira geração, a superfície é tratada com ácidos, por exemplo, o All Bond (ácido fosfórico a $10 \%$, ácido succínico $20 \%$ e HEMA) e o Clearfil Liner Bond (ácido cítrico 10\%), que tem a intenção de remover completamente a smear layer e disponibilizar o colágeno da matriz dentinária para a união química e mecânica.

Com o passar do tempo, esse sistema originou outros, mas com algumas modificações, como o Tenure Solution, que continha ácido fosfórico no condicionamento em combinação com o oxalato de alumínio e o ácido nítrico, o Gluma, composto por três elementos que usam EDTA como condicionador da dentina e HEMA e glutaraldeído como primer dentinário, o Scotchbond 2, com a utilização de uma solução aquosa de ácido maleico e HEMA para condicionar a dentina; o Prisma Universal Bond II e III incorporam glutaraldeído e é designado para aderir tanto a componentes inorgânicos quanto orgânicos da dentina, sendo que o primer desse sistema é o único da terceira geração que parece não alterar significantemente a smear layer.

$\mathrm{Na}$ adesão úmida, o condicionamento ácido total (Total-Etch ou AllEtch) e a formação de camada híbrida caracterizam os adesivos de quarta geração. Essa adesão úmida, proporcionada pela presença de radicais hidrofílicos nas formulações, proporciona maior união e garante propriedades adicionais de desempenho. A força de adesão, sensivelmente aumentada, garantiu o espaço e o desenvolvimento ainda maior dos adesivos de quarta geração. Vários experimentos têm demonstrado menores índices de microinfiltração quando comparados aos adesivos de terceira geração. 
Encontramos uma subclassificação, que considera os adesivos de quarta geração ${ }^{3}$ divididos em duas famílias: Universais e Simplificados.

Os sistemas adesivos Universais são aqueles que apresentam primer e adesivo em frascos separados, ou seja, exigem um passo distinto para a aplicação do primer e outro para a aplicação do adesivo. Em alguns casos, podem apresentar o primer dividido em dois frascos para serem misturados e utilizados na dentina em uma única aplicação.

Os adesivos do grupo Simplificado são aqueles que se apresentam num único frasco contendo primer e adesivo. São sistemas monocomponentes que apresentam os monômeros hidrofílicos em um diluente que pode ser álcool, acetona, etanol e água.

Ultimamente, foram lançados os adesivos considerados de quinta geração, ${ }^{3}$ isto é, aqueles que apresentam a propriedade self etch e possuem a propriedade de formação de camada híbrida e de tags em dentina, não necessitando, previamente, do passo de condicionamento ácido. Essa característica self etch garante a penetração dos monômeros em toda a área condicionada por desmineralizar o esmalte e a dentina, modificando a smear layer sem removê-la por completo e mantendo a Smear Plug, não deixando margem para a produção de falhas que podem acontecer quando do uso dos sistemas que necessitam do condicionamento prévio.

Devido a não utilização de ácidos, essa geração de adesivos não necessita de procedimento de lavagem, estabilizando as fibras colágenas e favorecendo a formação de camada híbrida, a qual permite alta força adesiva entre a estrutura dentária e a resina. ${ }^{5}$

Vários fatores podem contribuir para a eficiência ou não dos adesivos: dentina seca ou úmida, ${ }^{6}$ capacidade de penetração dos monômeros utilizados, ${ }^{7}$ contração de polimerização das resinas compostas, ${ }^{8,9}$ grau de polimerização das resinas, ${ }^{10}$ tamanho das partículas de carga da resina composta, ${ }^{10}$ microfendas formadas entre a dentina condicionada e penetrada pelo adesivo e a dentina não desmineralizada, falha essa denominada de nanoinfiltração, ${ }^{11,12}$ e a espessura da camada híbrida. ${ }^{13}$

O objetivo desta pesquisa foi avaliar in vitro a efetividade de dois sistemas adesivos autocondicionantes, um com carga $^{13}$ (Self-Etch Bond - Vigodent) e outro sem carga (Clearfil SE Bond Kuraray), sobre a dentina condicionada, utilizando uma resina composta microhíbrida Z-250 - 3M.

\section{REVISÃo DA LiTERATURA}

Youssef et al. ${ }^{13}$ avaliaram, comparativamente, quatro sistemas adesivos quanto à penetração na dentina e suas respectivas camadas híbridas e à profundidade de descalcificação. São eles: (Scotch-Bond Multi-Purpose da 3M, Prime \& Bond 2.O da Dentsply, Super D-Liner II da Sun Medical - Japan e Clearfil Liner Bond II da Kuraray - Japan). Para tanto, eles prepararam dez peças para cada sistema que, posteriormente, foram observadas em microscópio eletrônico de varredura. Os três primeiros sistemas apresentaram tags longos e camadas híbridas relativamente grossas quando comparados com Clearfil Liner Bond II. Os autores concluíram que os sistemas que apresentam soluções ácidas promovem uma descalcificação relativamente profunda, ocorrendo a formação de camadas híbridas espessas e de tags longos. O Clearfil Liner Bond II apresentou uma camada híbrida menos espessa e os tags mais curtos, em virtude da menor descalcificação causada por esse sistema.

Chain et al. ${ }^{14}$ fizeram um trabalho cuja intenção foi avaliar laboratorialmente quatro novos sistemas adesivos dentinários: Optibond Solo, (Kerr); 
Prime \& Bond 2.1, (Dentsply); Solid Bond, (Kulzer); e Syntac Sprint, (Vivadent). Foram realizados testes de resistência de união sob tensões de cisalhamento em dentina humana $(\mathrm{n}=10)$. Comparando-se os resultados obtidos nos quatro diferentes grupos, verificou-se que os sistemas Optibond Solo e Solid Bond apresentaram resistência de união significantemente maior que os sistemas Prime \& Bond 2.1 e Syntac Sprint. A interface dentina-sistema adesivo foi avaliada microscopicamente por meio da microscopia eletrônica de varredura.

Youssef et al. ${ }^{12}$ analisaram in vitro duas marcas de adesivos de quarta geração do sistema simplificado (Optisolo - Kerr, com carga, e Single Bond - 3M, sem carga) e duas marcas de resinas compostas (Prodigy - Kerr e Z100 - 3M), com o objetivo de verificação da adesividade na dentina. Oitenta corpos de prova, confeccionados a partir de molares humanos extraídos, foram incluídos em resina acrílica e desgastados até a exposição de dentina no sentido longitudinal e divididos em quatro grupos. Cones de resina composta foram aderidos a esses corpos de prova precedidos dos sistemas adesivos, seguindo a orientação dos fabricantes. Esses corpos foram submetidos a teste de tração e concluiu-se que houve diferença estatisticamente significante $(\mathrm{p}<0,01)$ entre os adesivos $(F=7,24)$, sendo que o adesivo Optisolo $(\mathrm{m}=11,03 \pm$ 4,23 ) apresentou maior resistência de união que o Single Bond $(\mathrm{m}=$ $8,37 \pm 4,54)$. Entre as duas resinas ( $F$ $=0,43$ ), não foi detectada diferença estatisticamente significante $(\mathrm{p}>0,05)$.

Cavalcanti ${ }^{15}$ avaliou a microinfiltração in vitro nas margens de esmalte $\mathrm{e}$ dentina em cavidades classe V, preparadas com alta rotação ou laser de Er:YAG e restauradas com os sistemas adesivos Single Bond (3M) ou Clearfil SE Bond (Kuraray). Foram utilizados 36 terceiros molares humanos, hígidos, nos quais foram confeccionadas cavidades classe $\mathrm{V}$ nas faces vestibulares e linguais de cada um deles, totalizando 72 cavidades. Os resultados foram submetidos ao teste estatístico de Mann-Whitney ao nível de significância de 5\%. Concluiuse que tanto os sistemas adesivos (Clearfil SE Bond e Single Bond) quanto os preparos com alta rotação e laser de Er: YAG apresentaram comportamentos semelhantes com relação à microinfiltração marginal. As margens em dentina mostraram maior infiltração quando comparadas às margens em esmalte.

Fermino et al. ${ }^{16}$ realizaram um estudo com a finalidade de avaliar quantitativamente in vitro a microinfiltração marginal em restaurações classe $\mathrm{V}$ em resina composta, utilizando-se diferentes sistemas adesivos: Clearfil SE Bond (Kuraray), One-up Bond F (Toruyama) e One Coat Bond (Coltene). Observou-se uma menor infiltração marginal na margem de esmalte $(\mathrm{p}<0,05)$. Na comparação entre os sistemas adesivos, observou-se que One Coat Bond apresentou uma maior infiltração, sendo estatisticamente diferente dos outros sistemas $(p<0,05)$. Na interação margem versus sistemas adesivos, o Clearfil SE Bond e o One up Bond $\mathrm{F}$ apresentaram diferença significante $(p<0,05)$. Podese concluir que nenhum sistema foi capaz de selar completamente as margens da restauração, tendo melhor vedamento em margem de esmalte.

O propósito da pesquisa realizada por Nunes et al., ${ }^{17} \mathrm{em} \mathrm{2006}$, foi verificar o grau de infiltração marginal em cavidades classe $\mathrm{V}$, vestibular e lingual, em 40 dentes pré-molares humanos divididos em quatro grupos e que, após ciclagem térmica a $5^{\circ} \mathrm{C} / 55^{\circ} \mathrm{C}$, foram imersos 
no corante azul de metileno a dois por cento por 24 horas, lavados e seccionados ao meio, no sentido vestíbulo-lingual, longitudinalmente, com um disco diamantado. A avaliação deles contemplou dois aspectos: 1 - tipos de adesivos dentinários: adesivo autocondicionante (Clearfil SE Bond), adesivo de frasco único com ácido (Single Bond) e adesivo convencional (Scotchbond Multi-Purpose), sendo todas as cavidades restauradas posteriormente com resina micro-híbrida (Z 250); e 2 - localização da parede cavitária (parede gengival em cemento e parede oclusal em esmalte). Os dados foram mensurados por meio de escores de 0 a 4 e processados estatísticamente pelo teste não paramétrico de Kruskal-Wallis. Os três tipos de sistemas adesivo-convencionais, simplificado e autocondicionante, não mostraram diferença estatística significante entre si. Também não houve diferença estatística significante entre parede oclusal e cervical.

No trabalho realizado por Cilli, ${ }^{18}$ em 2007, foram testadas as seguintes hipóteses nulas: 1) Não há diferença entre os valores de resistência de união entre resina restauradora e dentina, quando uma solução aquosa de glutaraldeído é aplicada como primer dentinário antes do emprego do agente adesivo; 2) Não há diferença entre os valores de resistência de união, quando a aplicação do mesmo sistema adesivo se dá em condições de dentina úmida ou seca. Dentes humanos foram selecionados e tiveram sua porção oclusal desgastada, expondo a parte média da dentina coronária para adesão. Quatro grupos foram formados, variando-se a aplicação ou não do primer de glutaraldeído e a condição de umidade dentinária: úmida ou seca. Após aplicação e fotopolimerização do sistema adesivo experimental, foram confeccionados blocos de resina com- posta de $4 \mathrm{~mm}$ de altura sobre a superfície oclusal, e os dentes foram preparados para o teste de microtração para a avaliação da resistência de união. Os resultados obtidos foram submetidos à análise de variância a um critério e teste de Tukey ('alfa' =0,05). A aplicação do primer de glutaraldeído aumentou significativamente os resultados de resistência de união. Não houve diferença estatística entre o mesmo sistema experimental, se aplicado em dentina seca ou úmida. A hipótese 1 não se confirma e aceita-se a hipótese 2 .

\section{Proposição}

O propósito desta pesquisa foi verificar o grau de infiltração marginal em cavidades classe $\mathrm{V}$ após ciclagem térmica, em função dos seguintes aspectos:

- tipos de adesivos dentinários: (adesivo autocondicionante sem carga + resina composta micro-híbrida; ataque ácido + adesivo de frasco único com carga + resina composta microhíbrida);

- localização da parede cavitária (oclusal em esmalte e gengival em cemento).

\section{Materiais e Métodos}

Foram utilizados nesta pesquisa dentes pré-molares humanos extraídos por razões ortodônticas.

Após a extração, os dentes foram recolhidos e armazenados em solução de formalina. Após a coleta, que se processou semanalmente, os dentes foram limpos por raspagem e fixados por mais 72 horas na mesma solução, evitando, assim, possível decomposição do tecido pulpar, passando-se, então, a uma armazenagem posterior em água destilada até o momento de uso.

Todos os dentes foram examinados com lupa com aumento de 10x, descartandose aqueles que apresentaram pequenas trincas, anomalias de esmalte dentário, 
abrasão, dentes de coloração amarelada intensa e com hipercementose. Ao todo, foram selecionados 30 pré-molares livres de cáries. Os dentes foram limpos com pedra-pomes e água com taça de borracha e lavados abundantemente com água para, então, serem realizadas cavidades padronizadas tipo classe $\mathrm{V}$, na vestibular e lingual de cada dente, segundo Barnes et al. ${ }^{19}$, totalizando 60 cavidades. Elas foram iniciadas com uma ponta diamantada número 1015 da KG Sorensen até alcançar um diâmetro de $3 \mathrm{~mm}$. A seguir, com uma broca carbide número 245 da SS White, aprofundava-se a cavidade até atingir $1,5 \mathrm{~mm}$. Ambas, ponta diamantada e broca carbide, foram utilizadas em alta rotação e refrigeradas com spray ar-água e com um cursor para mensuração da profundidade, sendo que, a cada cinco preparos cavitários, elas foram substituídas. O acabamento das paredes foi executado com a mesma broca carbide em baixa rotação e recortadores de margem gengival. As cavidades tipo classe $\mathrm{V}$ foram preparadas com a parede oclusal em esmalte dentário e a parede gengival em cemento dentário. As características finais das cavidades foram: parede axial convexa em todos os sentidos; paredes circundantes ligeiramente expulsivas formando ângulo reto com a superfície externa do dente; ângulos internos arredondados; ângulo cavo-superficial nítido e sem bisel e ausência de retenções adicionais.

Os 30 dentes com as cavidades preparadas foram divididos em três grupos de dez, que foram restaurados com os materiais a serem testados:

- Grupo I (controle) - sem condicionamento ácido + resina micro-híbrida e restaurações com a resina composta Z-250 - 3M. Após o preparo cavitário, o esmalte e a dentina foram lavados, abundantemente, por 30 segundos com água e não foram condicionados com ácido fosfórico. Foi removido o excesso de água com jatos de ar no esmalte, enquanto que na dentina foi utilizado o papel absorvente, deixando-a úmida. Foi aplicada a resina composta Z-250, em camadas oblíquas, primeiramente na cervical/axial, seguido da oclusal/ axial e finalmente na vestibular, com uma espátula de titânio e fotopolimerizada por 40 segundos cada camada com o aparelho Optilight 600.

- Grupo II - adesivo de frasco único com carga + ácido e resina microhíbrida (sistema da resina composta Z-250). Após o preparo cavitário e o condicionamento com ácido fosfórico a $35 \%$, foram aplicadas duas camadas consecutivas do adesivo (Self-Etch Bond - Vigodent) no esmalte e na dentina, seguido de secagem rápida por dois a cinco segundos com ar e fotopolimerizado por dez segundos. A resina composta Z-250 foi colocada em incrementos inferiores a $2,5 \mathrm{~mm}$ de profundidade, com espátula de titânio, sendo cada camada incremental fotopolimerizada por 40 segundos até completar a restauração.

- Grupo III - adesivo autocondicionante sem carga + resina microhíbrida (sistema da resina composta Z-250). Preparadas as cavidades, foram condicionados o esmalte e a dentina e, mantendo-se a dentina úmida, foi aplicado o sistema adesivo autocondicionante (Clearfil SE Bond - Kuraray) na cavidade, com um aplicador próprio, por 30 segundos. Os excessos foram removidos com jatos de ar (três a cinco segundos) e fotopolimerizado por dez segundos. Foi aplicada uma segunda camada do mesmo material obedecendose o mesmeo procedimento. A resina composta foi aplicada em incrementos inferiores a 2,5 $\mathrm{mm}$, sendo cada camada fotopolimerizada por 40 segundos até o preenchimento total da cavidade. 
Concluídas as restaurações de todos os grupos, o acabamento delas constituiu na remoção dos excessos grosseiros com lâmina de bisturi número 15. Os dentes, assim preparados, foram imersos em água destilada por 24 horas, em estufa por $37^{\circ} \mathrm{C}$. Decorrido esse tempo, foram realizados o acabamento e polimento das restaurações com discos Sof-lex sequenciais. Os dentes foram, então, impermeabilizados com duas camadas de Araldite de presa rápida e duas de esmalte para unhas, em cores diferentes para cada grupo, preservando-se $2 \mathrm{~mm}$ ao redor das restaurações sem a impermeabilização. Após o período de secagem (aproximadamente uma hora), os dentes foram submetidos à ciclagem térmica.

A ciclagem térmica utilizou temperaturas de $5^{\circ} \mathrm{C}$ e $55^{\circ} \mathrm{C}$, com um total de cem ciclos, de 30 segundos para cada um dos extremos de temperatura. Para realizar a ciclagem, os dentes foram colocados no corante azul de metileno a $2 \%$ e assim mantidos durante a sequência de ciclos realizados. Para o controle das temperaturas necessárias, foram utilizados termômetros próprios. Completados os ciclos, os dentes foram mantidos em azul de metileno a $2 \%$ por 24 horas, a $37^{\circ} \mathrm{C}$.

Concluída a ciclagem térmica, os espécimes foram lavados, escovados e mantidos em água corrente por duas horas e por igual tempo em condição ambiente para secagem natural. Uma vez secos os dentes, a película impermeabilizante foi removida por raspagem e estes foram fixados em uma placa de madeira por meio de godiva de baixa fusão. Os dentes foram então seccionados ao meio no sentido vestíbulo lingual, longitudinalmente, com um disco diamantado fixado em um micrótomo próprio, sob refrigeração à água. $\mathrm{O}$ excesso de água foi removido colocando- se os dentes seccionados em papel absorvente por 30 minutos.

A avaliação da infiltração marginal foi realizada por três examinadores calibrados entre si, com uma lupa com aumento de 10x e classificada segundo o grau de penetração do corante. Em consenso, os examinadores, por análise prévia, escolheram somente uma das secções, ou seja, a que obteve maior grau de penetração do corante.

O grau de infiltração foi atribuído segundo o critério de escores modificados por Crim e Garcia-Godoy: ${ }^{20}$

0 Nenhuma infiltração;

1 Infiltração até a metade da parede circundante;

2 Infiltração em toda a parede circundante;

3 Infiltração na parede circundante e axial;

4 Infiltração na parede circundante, axial e em direção à polpa.

Os dados obtidos foram organizados e submetidos à análise estatística por meio do teste não paramétrico de Mack-Skillings combinado com o de Kruskal-Wallis, complementados pelos respectivos testes de contrastes entre variáveis, duas a duas. ${ }^{21}$

\section{Resultados e Discussão}

Os dados de infiltração foram descritos pelos parâmetros de média, mediana, $1^{\circ}$ quartil e $3^{\circ}$ quartil. A Tabela 1 apresenta os resultados obtidos por meio de escores médios; para comparação entre os grupos, foi utilizado o teste de Kruskal-Wallis e, quando este mostrou diferença estatisticamente significante, foi utilizado o teste de Dunn para comparações múltiplas. Para a comparação entre as regiões de um mesmo grupo, foi utilizado o teste de Friedman. ${ }^{21}$

Em todos os testes estatísticos foi adotado nível de significância de 5\%. 
TABELA 1 - EsCORES MÉDIOS DE INFILTRAÇÃO MARGINAL DOS GRUPOS NAS QUATRO REGIÕES ESTUDADAS, E RESUltado DO TESTE DE KRUSKal-Wallis.

\begin{tabular}{lllll}
\hline Grupo & $\begin{array}{l}\text { Esmalte } \\
\text { Vestibular }\end{array}$ & $\begin{array}{l}\text { Esmalte } \\
\text { Lingual }\end{array}$ & $\begin{array}{l}\text { Cemento } \\
\text { Vestibular }\end{array}$ & $\begin{array}{l}\text { Cemento } \\
\text { Lingual }\end{array}$ \\
\hline I & $4,0^{\mathrm{a}}$ & $4,0^{\mathrm{a}}$ & $4,0^{\mathrm{a}}$ & $4,0^{\mathrm{a}}$ \\
II & $2,2^{\mathrm{b}}$ & $2,7^{\mathrm{ab}}$ & $1,5^{\mathrm{b}}$ & $2,4^{\mathrm{b}}$ \\
III & $0,9^{\mathrm{b}}$ & $1,3^{\mathrm{b}}$ & $2,4^{\mathrm{b}}$ & $2,0^{\mathrm{b}}$ \\
\hline $\begin{array}{l}\text { Dentro de cada grupo, regiões com a mesma } \\
\text { diferença estatisticamente significante entre si. }\end{array}$
\end{tabular}

Obtiveram-se os seguintes resultados grupo a grupo:

- Grupo I (controle) - sem condicionamento ácido + resina microhíbrida Z-250 - 3M - foi o que obteve maiores escores de infiltração marginal tanto em esmalte quanto em cemento, sendo estatisticamente significante com relação ao grupo III e não significante em relação ao grupo II, no esmalte lingual (Gráfico 1).

- Grupo II - adesivo autocondicionante (Self-Etch Bond - Vigodent) com carga + ácido e resina micro-híbrida (sistema da resina composta Z-250). Os escores de infiltração marginal não foram estatisticamente significantes entre esmalte e cemento e entre o grupo III. E foram significantes em relação ao grupo I, com exceção do esmalte lingual.

- Grupo III - adesivo autocondicionante sem carga (Clearfil SE Bond - Kuraray) + resina micro-híbrida (sistema da resina composta Z-250). Obtiveram-se numericamente os menores escores de infiltração marginal, mas não foram estatisticamente significantes entre o esmalte e cemento e entre o grupo II, mas foi significante em relação ao grupo I.

Gráfico 1 - ESCORE MÉDIO PARA CADA GRUPO NAS QUATRO REGIÕES ESTUDADAS.

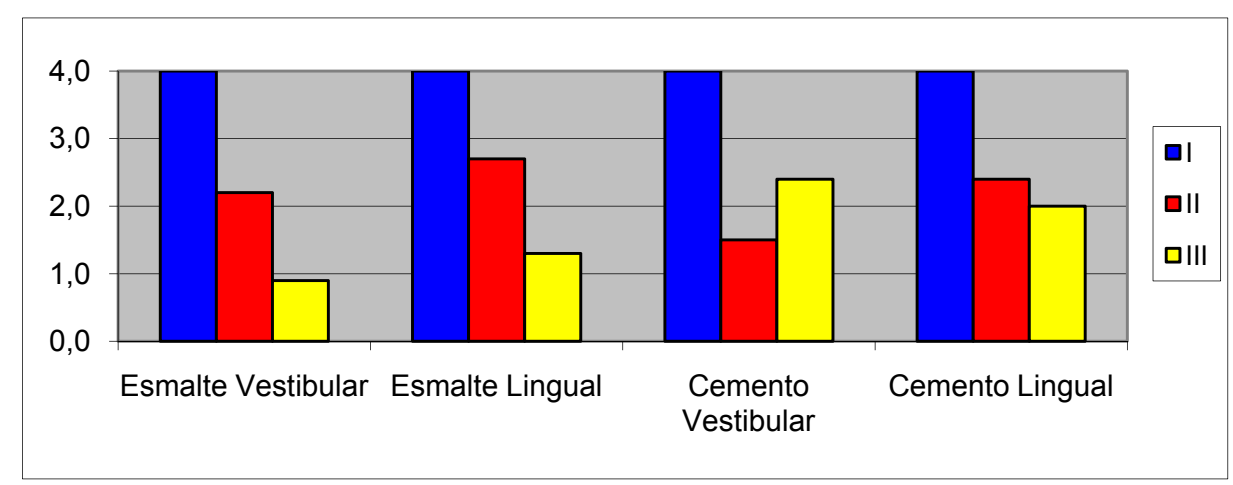

Os sistemas adesivos foram avaliados quanto à penetração na dentina e suas respectivas camadas híbridas e à profundidade de descalcificação. São eles: Scotch-bond Multi-Purpose (3M), Prime \& Bond 2.O (Dentsply), Super D-Liner II (Sun Medical - Japan) e Clearfil Liner Bond II (Kuraray - Ja- pan). Os três primeiros sistemas apresentaram tags longos e camadas híbridas relativamente grossas quando comparados com Clearfil Liner Bond II. Conclui-se que os sistemas que apresentam soluções ácidas promovem uma descalcificação relativamente profunda, ocorrendo a formação de camadas híbridas 
espessas e de tags longos. O Clearfil Liner Bond II apresentou uma camada híbrida menos espessa e os tags mais curtos, em virtude da menor descalcificação causada por esse sistema. ${ }^{7}$

Foram testados quatro novos sistemas adesivos dentinários: Optibond Solo, (Kerr); Prime \& Bond 2.1 (Dentsply); Solid Bond (Kulzer) e Syntac Sprint (Vivadent). Foram realizados testes de resistência de união sob tensões de cisalhamento em dentina humana. Comparando-se os resultados obtidos nos quatro diferentes grupos, verificou-se que os sistemas Optibond Solo e Solid Bond apresentaram resistência de união significantemente maior que os sistemas Prime \& Bond 2.1 e Syntac Sprint. A interface dentinasistema adesivo foi avaliada microscopicamente por intermédio da microscopia eletrônica de varredura. ${ }^{14}$

Foram avaliadas in vitro duas marcas de adesivos de quarta geração do sistema simplificado (Optisolo - Kerr, com carga, e Single Bond - 3M, sem carga) e duas marcas de resinas compostas (Prodigy - Kerr e Z100 - 3M), com o objetivo de verificação da adesividade na dentina. Os resultados obtidos foram transformados em MPa de acordo com a área de adesão e submetidos à análise estatística pela ANOVA $^{21}$. Pelos resultados obtidos, concluiu-se que houve diferença estatisticamente significante $(p<0,01)$ entre os adesivos $(F=7,24)$, sendo que o adesivo Optisolo ( $\mathrm{m}=$ $11,03 \pm 4,23)$ apresentou maior resistência de união que o Single Bond $(\mathrm{m}=$ $8,37 \pm 4,54)$. Entre as duas resinas $(\mathrm{F}=$ $0,43)$, não foi detectada diferença estatisticamente significante $(p>0,05) .{ }^{12,21}$

Avaliou-se in vitro a microinfiltração marginal em restaurações classe $\mathrm{V}$ em resina composta, utilizando-se diferentes sistemas adesivos: Clearfil SE Bond (Kuraray), One-up Bond F (Toruyama) e One Coat Bond (Coltene). A análise da microinfiltração marginal foi feita por meio de um sistema de imagem digitalizada, composta por um microscópio (Carl Zeiss-Jena), acoplado a um microcomputador e, então, utilizado o programa KS 300 v. 2.00. Observou-se uma menor infiltração marginal na margem de esmalte $(\mathrm{p}<0,05)$. $\mathrm{Na}$ comparação entre os sistemas adesivos, observou-se que One Coat apresentou uma maior infiltração, sendo estatisticamente diferente dos outros sistemas $(\mathrm{p}<0,05)$. Na interação margem versus sistemas adesivos, o Clearfil SE Bond e o One up Bond $\mathrm{F}$ apresentaram diferença significante $(p<0,05)$. Pode-se concluir que nenhum sistema foi capaz de selar completamente as margens da restauração, tendo melhor vedamento em margem de esmalte. ${ }^{16}$

Todos os adesivos dentinários testados tiveram infiltração marginal, porém em graus variáveis, apesar do condicionamento ácido aliado ao uso da técnica da dentina úmida, da técnica incremental para inserção da resina composta, a fim de reduzir o fator $\mathrm{C}$, o acabamento e polimento após 24 horas. Todos esses cuidados visaram diminuir a expansão higroscópica da resina composta.

\section{ConClusões}

1. Dos sistemas adesivos testados, nenhum deles foi capaz de impedir a infiltração marginal tanto em esmalte quanto em cemento.

2. Não houve diferença estatística significante entre as paredes oclusal (esmalte) e cervical (cemento) e as faces vestibular e lingual.

3. Os sistemas adesivos autocondicionante (com carga e sem carga) não mostraram diferença estatística significante entre si, apesar do adesivo autocondicionante sem carga apresentar os menores escores de infiltração marginal.

4. Houve diferença estatística significante entre o grupo I (controle) e os grupos II e III, com exceção do grupo II (esmalte lingual). 


\section{REFERÊNCIAS BiBLIOGRÁFICAS}

1. Nakabayashi N. Hybridization of natural tissues containing collagen with biocompatible materials: adhesion to tooth substrates. J Biomed Mater Res 1989; 23:265-73.

2. Buonocore MG. A simple method of increasing the adhesion of acrylic materials to enamel surfaces. J Dent Res Dec 1955; 34 (6): 849-853.

3. Susin $\mathrm{AH}$. Adesivos dentinários: classificação, composição e aplicações clínicas. Rev Dent on-line Set-Dez 2000;1(1). Available from: URL: $<$ http.br/dentisticaonline/artigo2. html $>$.

4. Susin AH. Esmalte, dentina, smear layer e condicionadores na odontologia adesiva. Rev Dent on-line SetDez 2000; 1(1). Available from: URL: $<$ http.br/ dentisticaonline/art4.html $>$.

5. Rastelli, Alessandra Nara de Souza, Andrade, Laura Helena Hidalgo, Oliveira Júnior, Osmir Batista. Utilização clínica de um novo sistema adesivo autocondicionante. Rev Dent on-line 2001, 2 (5). < http.br/dentisticaonline/ art5-clearfillclinico.html $>$.

6. Tay FR, Gwinnett AJ, Pang KM, Wei $\mathrm{SH}$. Micromorphological sprectrum from overdrying to overwetting acidconditioned dentin in water-free, acetone-based, single-bottle primer/ adhesives. Dent Mater Jul 1996; 12(4):236-244.

7. Youssef N, Guaraldi E, Sato CT, Hayashi RF Estudo comparativo de quatro filosofias adesivas quanto à penetração na dentina. Rev Assoc Paul Cir Dent Mai-Jun 1998; 52 (3): 236-239.

8. Davidson CL, Gee AJ. Relaxation of polymerization contraction stress by flow in dental composites. J Dent Res 1984; 63 (2):146- 48.

9. Perdigão J, Lambrechts $P$, Van Meerbeek B, Braem M, Yildiz E, Yücel $\mathrm{T}$, Vanherle G.The interaction of adhesive systems with human dentin. Am J Dent Aug 1996; 9 (4):167-173.

10. Turbino ML. Contribuição ao estudo da microdureza Knoop de resinas compostas na região próxima à área de união à dentina. São Paulo, 1997. Tese
(Doutorado) - Faculdade de Odontologia, Universidade de São Paulo.

11. Lago CCL. Avaliação da influência do tempo de abertura dos frascos de sistemas adesivos na microinfiltração marginal em cavidades de classe $\mathrm{V}$ de dentes restaurados com resina composta. Salvador, 2006. Tese (Mestrado) - Faculdade de Odontologia de Salvador, Universidade Federal da Bahia.

12. Sano H, Takatsu T, Ciucchi B, Horner JA, Matthews WG, Pashley DH. Nanoleakage: leakage within the hybrid layer. Oper Dent Jan-Feb 1995a; 20(1):18-25.

13. Youssef JA, Turbino ML, Youssef MN, Matson E. Resistência de união à dentina de resinas compostas associadas a sistemas adesivos com e sem carga. Pesqui Odontol Bras Abr-Jun 2001;15 (2):157-160.

14. Chain MC, Aust S, Heleno RTB, Lopes GC. Avaliação laboratorial de sistemas adesivos de última geração. $\mathrm{J}$ Bras Clin Estet Odontol Mar-Abr 2000; 4 (20):61-4.

15. Cavalcanti RCM. Avaliação da microinfiltração marginal de dois sistemas adesivos em cavidades preparadas com laser Er: YAG ou alta rotação. Camaragibe, 2003. Tese (Mestrado) - Faculdade de Odontologia, Universidade de Pernambuco.

16. Fermino ML, Dibb P, Guenka R. Avaliação quantitativa "in vitro" da microinfiltração marginal em restaurações classe $\mathrm{V}$ em resina composta, utilizando-se sistemas adesivos total e self-etching. Rev Paul Odontol JanFev 2004; 26(1): 20-3.

17. Nunes OBC, Abreu PH, Pazim MSL, Nunes NA, Lauris, JRP, Vasconcelos DA et al.

Infiltração marginal utilizando três tipos de adesivos dentinários com restaurações de resina composta. Rev Fac Odontol Lins Jan-Dez 2006;18(1):7-18.

18. Cilli R. Contribuição do glutaraldeído como componente de sistemas adesivos dentinários. Bauru, 2007. Tese (Doutorado) - Faculdade de Odontologia de Bauru, Universidade de São Paulo. 
19. Barnes DM; McDonald NJ; Thompson VP; Blank LW; Shires PJ. Microleakage in facial and lingual class 5 composite restorations: a comparison. Oper Dent 1994; 19: 133-7.

21. Mack GA, Skillings JH. A Friedman - type tank test for main effects in a two-factor ANOVA. J Amer Statist Ass 1980; 75 (372): 947-51.
22. Webber LBM. Avaliação do selamento marginal de diferentes adesivos dentários em restaurações de resinas compostas: estudo in vitro. Salvador, 1998. Tese (Mestrado) - Faculdade de Odontologia, Universidade Federal da Bahia.

Recebimento do artigo: 23/1/08 Aprovado: 20/5/09 